Relations industrielles

Industrial Relations

\title{
Les travailleurs et la culture
}

Volume 9, numéro 3, juin 1954

URI : https://id.erudit.org/iderudit/1022874ar

DOI : https://doi.org/10.7202/1022874ar

Aller au sommaire du numéro

\section{Éditeur(s)}

Département des relations industrielles de l’Université Laval

\section{ISSN}

0034-379X (imprimé)

1703-8138 (numérique)

Découvrir la revue

Citer ce document

(1954). Les travailleurs et la culture. Relations industrielles / Industrial Relations, 9(3), 295-296. https://doi.org/10.7202/1022874ar
Résumé de l'article

Conclusions de la 35ème Semaine Sociale Wallonne 27 au 30 août 1953.
Tous droits réservés @ C Département des relations industrielles de l’Université Laval, 1954
Ce document est protégé par la loi sur le droit d'auteur. L’utilisation des services d'Érudit (y compris la reproduction) est assujettie à sa politique d'utilisation que vous pouvez consulter en ligne.

https://apropos.erudit.org/fr/usagers/politique-dutilisation/ 


\section{INFORMATIONS}

\section{LES TRAVAILLEURS ET LA CULTURE}

\section{Conclusions de la 35ème Semaine Sociale Wallonne 27 au 30 août 1953}

Le but de la civilisation et de la culture est d'achever le monde aux fins d'achever l'homme.

Le Christianisme confère à la personne une dignité éminente, dignité qui est le fondement de ses droits et de ses exigences d'épanouissement. Aux périodes d'ascension du christianisme correspondent naturellement des périodes d'ascension de la civilisation.

Le libéralisme des XVIIIème et XIXème siècles qui a nié les valeurs spirituelles a conduit à l'asservissement du monde ouvrier. La culture a été réservée à la bourgeoisie. La conception de la culture s'est rétrécie à l'image du monde bourgeois, elle n'a plus été esprit et vie, elle est devenue un décor sans aucune influence sur la vie des hommes.

Le marxisme a voulu libérer les travailleurs de leur asservissement mais rejetant comme le libéralisme toute valeur spirituelle, il n'a pu être un grand mouvement d'ascension humaine. Les essais de réalisation en Russie Soviétique prouvent' qu'il ne peut conduire qu'à la négation des droits de l'homme, la société devenant en ses lieu et place la valeur éminente.

A une civilisation qui ne cesse de nier l'homme, il faut substituer une civilisation vraiment humaine où les hommes puissent s'épanouir dans les cadres d'une société qui tienne compte de toutes les valeurs constitutives de la personne.

La culture doit être considérée comme l'épanouissement de toutes les virtualités humaines. C'est dans toute sa vie que l'homme se réalise en tant que personne; c'est chaque jour, dans l'effort constamment renouvelé pour connaître, expliquer, juger, pour se réaliser et accomplir son destin que l'homme se personnalise.

Trop longtemps, la culture a été coupée de la vie réelle, il faut l'y réintroduire.

Le travail doit redevenir pour l'homme une source de joie par la pleine conscience de l'apport social qu'il constitue et de sa signification rédemptrice.

Cela ne sera pas tant que les conditions du travail, les relations sociales dans le cadre du travail, tout le cadre de la vie économique n'auront subi les transformations qui les rendront plus humanisantes, plus personnalisantes. Cet effort pour réaliser de nouvelles structures de l'entreprise et de l'économie doit s'inscrire dans les plus hautes préoccupations des patrons, de toutes les élites chrétiennes et des gouvernants.

La famille et le milieu familial constituent par excellence un milieu culturel. Trop d'obstacles s'opposent encore à cette mission de la famille en milieu populaire; propagande de doctrines subversives, d'idées malsaines, ressources insuffisantes, absence de maison réellement familiale, manque de préparation aux tâches familiales. Tous ces obstacles doivent être levés, afin que la famille populaire puisse redevenir un foyer culturel.

L'enseignement doit développer la culture, il doit aboutir à un véritable humanisme. Il a trop été conçu d'une façon utilitaire, comme un apprentissage de con- 
naissances nécessaires à l'exercice de la profession. L'enseignement a été conçu à l'usage des bourgeois, il doit se démocratiser, devenir accessible à tous et être pour tous, quelle que soit la fonction à laquelle il prépare, une source d'épanouissement humain.

La disposition d'un temps raisonnable de loisirs revêt une grande importance pour l'accession des travailleurs à la culture.

Le temps des loisirs peut constituer une occasion de grand enrichissement culturel par la vie de famille qu'il permet et par la possibilité qu'il donne d'ét'endre ses connaissances et d'apprécier les richesses du monde, richesses naturelles ou créées par les hommes. Il faut constater cependant que trop souvent le temps de loisirs est plutôt cause d'abrutissement. Il ne convient cependant pas d'organiser trop techniquement les loisirs, une large place doit être laissée à la liberté. Les pouvoirs publics ne peuvent cependant pas rester indifférents à ce problème; dans un souci d'élévation du peuple, ils doivent veiller à la moralité des loisirs organisés et encourager les initiatives culturelles.

L'avènement de la démocratie politique est une des grandes conquêtes du siècle: la possibilité pour chacun de s'intéresser aux problèmes politiques qui ne sont autres que ceux de l'aménagement de la Cité pour le bien de tous. Par Cité, il faut maintenant entendre, la commune, la province, la nation, le monde, dès maintenant chacun est citoyen du monde. L'intérêt porté à tous ces problèmes, la participation à leur discussion est une source de culture dont ne profitent pas assez les travailleurs, ni du reste l'ensemble des citoyens. Il reste beaucoup à faire par les partis pour créer les conditions favorables à une telle participation.

Le mouvement ouvrier a constitué dans le passé le milieu naturel où les travailleurs ont pu réaliser leur ascension culturelle par toutes les richesses et valeurs qu'il leur a fait découvrir.

Si le marxisme a mis en veilleuse certaines de ces valeurs, le mouvement ouvrier chrtien est venu rétablir la synthèse entre les «besoins 》 matériels et les aspirations spirituelles.

Celui-ci doit veiller à garder dans ses formes d'organisation toutes les richesses de l'association humaine dans laquelle chacun se sent participant et collaborateur, - lié aux autres par les liens intimes de la fraternité et de la solidarité pour l'édification d'un même idéal.

Conscient de sa conception de la personne humaine, le mouvement ouvrier chrétien doit, par tous moyens en son pouvoir, promouvoir la promotion culturelle des travailleurs, depuis l'extension de leurs connaissances jusqu'à leur participation aux plus hautes réalités spirituelles qui révèlent la foi en Dieu et la pratique religieuse. Il doit les inviter à toutes les formes d'action sociale et politique, et leur en montrer les richesses, comme il doit les aider à retirer de leurs loisirs un enrchissement culturel. Dans toute son action revendicatrice, soit en vue d'avantages matériels, soit en vue de transformation de structures économiques et sociales, il doit placer au premier plan de ses préoccupations, l'épanouissement de la personne du travailleur.

La culture est pour l'homme la possibilité de se situer en face de sa mission terrestre et de son destin éternel et de se réaliser en fonction de ce destin. Il n'est pas de plus haute mission pour le mouvement ouvrier chrétien que de faire accéder les travailleurs à cette possibilité. 